\title{
Impact of Cardiac Function Improvement on Cardiac Surgery Associated Acute Kidney Injury for Patients with Preoperative Renal Dysfunction
}

Jiarui $X u$

Zhongshan Hospital Fudan University

Xin Chen

Zhongshan Hospital Fudan University

Jing Lin

Zhongshan Hospital Fudan University

Yang Li

Zhongshan Hospital Fudan University

\section{Bo Shen}

Zhongshan Hospital Fudan University

\section{Wuhua Jiang}

Zhongshan Hospital Fudan University

Zhe Luo

Zhongshan Hospital Fudan University

Chunsheng Wang

Zhongshan Hospital Fudan University

Xiaoqiang Ding

Zhongshan Hospital Fudan University

Jie Teng1

Zhongshan Hospital Fudan University

Wenlv Lv ( $D$ lv.wenlv@zs-hospital.sh.cn )

Zhongshan Hospital Fudan University

\section{Research article}

Keywords: renal dysfunction, cardiac surgery, acute kidney injury, cardiac function

Posted Date: August 19th, 2020

DOI: https://doi.org/10.21203/rs.3.rs-58733/v1 
License: (c) (i) This work is licensed under a Creative Commons Attribution 4.0 International License. Read Full License 


\section{Abstract}

Background: We aim to investigate whether the postoperative cardiac function improve or not would affect the risk of cardiac surgery associated acute kidney injury (AKI) for patients with preoperative renal dysfunction.

Method: Data from patients underwent cardiac surgery from April 2012 to February 2016 were collected. Renal dysfunction was defined as preoperative $\mathrm{SCr}>1.2 \mathrm{mg} / \mathrm{dL}$ (females) or $>1.5 \mathrm{mg} / \mathrm{dL}$ (males). Patients were grouped as normal renal function group, renal dysfunction with chronic kidney disease (CKD group), and non CKD group. $\triangle$ LVEF=postoperative LVEF - preoperative LVEF. Cardiac function improved was defined as $\triangle L V E F \geq 10$. Patients were further divided into non $C K D$ \& cardiac function improved (non CKD+), non CKD \& cardiac function not improved (non CKD-), CKD \& cardiac function improved (CKD+) and CKD \& cardiac function not improved (CKD-) subgroups.

Results: A total of 8,661 patients were allocated as normal renal function $(n=7,903)$, non $\operatorname{CKD}(n=662)$ and CKD $(n=136)$ groups. Both non CKD and CKD groups had higher AKI incidence than normal function group (39.5\% vs $30.0 \%, \mathrm{P}<0.001 ; 61.8 \%$ vs $30.0 \%, \mathrm{P}<0.001)$, and non $\mathrm{CKD}+$ group had the similar AKI incidence with normal function group ( $30.9 \%$ vs $30.0 \%, P=0.729)$. Multivariate logistic regression analysis revealed that non CKD-, CKD+ and CKD- were significant risk factors, whereas non CKD+ was not a significant risk factor for postoperative AKI. The SCr at discharge in non CKD+ subgroup was significantly lower than its preoperative $\mathrm{SCr}(1.4 \pm 0.8$ vs $1.7 \pm 0.9 \mathrm{mg} / \mathrm{dL}, P=0.020)$.

Conclusions: For renal dysfunction patients with no CKD, the risk of postoperative AKI did not exist if the cardiac function improved after surgery. For CKD patients, the risk of postoperative AKI increase regardless whether the cardiac function improved or not.

\section{Introduction}

The incidence of cardiac surgery associated acute kidney injury (CSA-AKI) was high which often lead to poor outcomes in short and long-term [1,2]. Patients undergoing cardiac surgery commonly have cardiorenal syndrome [3]. Acute or chronic heart failure can lead to a deterioration in renal function and vice versa $[4,5]$. It has been reported that preoperative renal dysfunction has an incidence $>20 \%[6]$, and was an important risk factor for CSA-AKI patients. Of the commonly used risk scores for cardiac surgery, including the Cleveland and Mehta scores, pre-existing renal dysfunction is an independent high-risk factor for AKI $[7,8,9]$. Shavit et al. found that $44 \%$ of octogenarians who underwent cardiac surgery had preoperative serum creatinine $(\mathrm{SCr})>1.2 \mathrm{mg} / \mathrm{dL}$, which was independently associated with an increased incidence of postoperative cerebral vascular accidents [10]. Holzmann et al. carried out an analysis of 36,284 patients who underwent coronary artery bypass grafting (CABG) surgery and reported that preoperative moderate renal dysfunction (eGFR $15-45 \mathrm{~mL} / \mathrm{min} / 1.73 \mathrm{~m}^{2}$ ) was an independent risk for postoperative all-cause mortality[11]. Accordingly, preoperative renal dysfunction might be considered to be contraindicated for cardiac surgery in clinical practice. 
Previous studies proved that impaired renal function can be improved by cardiac resynchronization or left ventricular assist devices $[12,13]$. We hypothesized that part of preoperative renal dysfunction might be reversible, for cardiac surgery may ameliorate the hypoperfusion and ischemia of the kidney, thus may improve the renal function. Because most studies about renal dysfunction have mainly looked at chronic kidney disease (CKD), not slight renal dysfunction[6]. Therefore, we aim to investigate the impact of cardiac function improvement on patients with preoperative renal dysfunction.

\section{Methods}

\section{Patients}

In this retrospective observational study, we collected data from patients who underwent cardiac surgery in our hospital between April 2012 and February 2016. The Ethical Committee of the Hospital approved the study (No. B2016-147R). Patients were excluded if they were <18 years old, had aorta aneurysm surgery or heart transplantation, or had preoperative renal replacement therapy (RRT).

\section{Definitions}

Renal dysfunction was defined as preoperative $\mathrm{SCr} \geq 1.2 \mathrm{mg} / \mathrm{dL}$ (females) and $\geq 1.5 \mathrm{mg} / \mathrm{dL}$ (males) [10, 14]. CKD was diagnosed according to the Kidney Disease: Improving Global Outcomes criteria [15]: $\nabla$. Kidney damage for $\geq 3$ months was defined by structural or functional abnormalities of the kidney, with or without a decreased glomerular filtration rate (GFR); ख. GFR $<60 \mathrm{~mL} / \mathrm{min} / 1.73 \mathrm{~m}^{2}$ for $\geq 3$ months, with or without kidney damage. GFR was calculated by the EPI equation formula [16]. Renal ultrasound abnormal included small kidney size, increased renal cortex echogenicity, obvious renal cyst et al. AKI was defined according to the KDIGO 2012 criteria [17] as the absolute value of an SCr increase $\geq 26.5$ $\mathrm{mmol} / \mathrm{L}$ within $48 \mathrm{~h}$ or an increase $>50 \%$ compared to the baseline values within 7 days or a urine output $<0.5 \mathrm{~mL} / \mathrm{kg} / \mathrm{h} \geq 6 \mathrm{~h}$.

$\triangle L V E F=$ postoperative LVEF - preoperative LVEF. Cardiac function improved was defined as $\triangle L V E F \geq 10$. Preoperative LVEF was measured routinely at hospital admission using transthoracic echocardiography (Phillips Medical Systems, Andover, MA, US) and calculated using the Simpson apical biplane method. Postoperative LVEF was recorded as the last measurement before discharge after the patient was transferred from the intensive care unit (ICU) to the ward. No cardiotonic drugs were used at that time, which may have impacted on the results of our study. SCr at discharge was recorded as the last measurement before discharge.

\section{Groups and endpoints}

All patients were allocated into normal renal function (Normal group), preoperative renal dysfunction with no CKD (non CKD group), and CKD group. The non CKD and CKD groups were further divided into non CKD \& cardiac function improved (non CKD+), non CKD \& cardiac function not improved (non CKD-), CKD \& cardiac function improved (CKD+) and CKD \& cardiac function not improved (CKD-) groups (Figure 1). 
The main primary end-points were AKI incidence and $\mathrm{SCr}$ at discharge. The secondary endpoints were inhospital mortality, lengths of ICU and hospital stays.

\section{Statistical analysis}

All data were analyzed using SPSS for Windows (ver. 22.0. Chicago, SPSS Inc., US). Normally distributed data are expressed as the mean \pm standard deviation; Non-parametric data are expressed as the median (25-75\% interquartile range). Groups were compared using one-way ANOVA. Tukey's pairwise comparisons were used in ANOVA for the adjustment of the family wise error rate. Wilcoxon tests were used to analyze non-parametric variables and chi-squared tests for group comparisons. The univariable logistic regression was first carried out and the factors with statistical significant differences were selected for the multivariate logistic regression model to investigate the influence of multiple factors on the incidence of AKI. A P value $<0.05$ was considered to be statistically significant.

\section{Results}

\section{Basic characteristics}

Of 8,661 patients who underwent cardiac surgery between April 2012 and February 2016, there were $7,903(91.2 \%)$ cases in the Normal group, $622(7.2 \%)$ in the non CKD group and $136(1.6 \%)$ in the CKD group. Patients in the non CKD group were younger than in the CKD group. Preoperative LVEF was significantly lower in the non CKD and CKD groups compared to the Normal group. Preoperative SCr was significantly higher in the non CKD and CKD groups than in the Normal group (Table 1).

\section{AKI incidence and outcomes in non CKD, CKD and normal groups}

The AKI incidence in the non CKD and CKD groups was higher than in the Normal group $(39.5 \%$ vs $30 \%, P$ $<0.001 ; 61.8 \%$ vs $30 \%, P<0.001)$ and the AKI incidence in the non CKD group was significantly lower than in the CKD group (39.5\% vs 61.8\%, $P<0.001)$. There was no significant difference between $\mathrm{SCr}$ at discharge and preoperative SCr in the non CKD group ( $1.7 \pm 0.8$ vs $1.6 \pm 1.1 \mathrm{mg} / \mathrm{dL}, P=0.465)$, while $\mathrm{SCr}$ at discharge was significantly higher than preoperative SCr in the CKD group (1.6 \pm 0.6 vs $2.3 \pm 1.4$ $\mathrm{mg} / \mathrm{dL}, P=0.006)$. The ICU and hospital stay in the non CKD and CKD groups were significantly longer than in the Normal group (Table 2).

\section{AKI incidence and outcomes in the subgroups}

There was no significant difference of AKI incidence between non CKD+ subgroup and the Normal group (30.9\% vs 30.0\%, $P=0.729$ ), but the AKI incidences in the non CKD-, CKD+, CKD- subgroups were significantly higher than in the Normal group. The incidence of AKI-RRT in the non CKD+, non CKD-, CKD+, CKD- subgroups were significantly higher than in the Normal group.

The SCr at discharge was significantly lower than preoperative SCr in the non CKD+ subgroup $(1.4 \pm 0.8$ vs $1.7 \pm 0.9 \mathrm{mg} / \mathrm{dL}, P=0.020)$, and $\mathrm{SCr}$ at discharge in the CKD- subgroup was significantly higher than 
the preoperative SCr levels in the same subgroup $(2.5 \pm 1.7$ vs $1.5 \pm 0.4 \mathrm{mg} / \mathrm{dL}, P=0.017)$.

The hospital mortality in the CKD- and non CKD- subgroups was significantly higher than in the Normal group $(15.4 \%$ vs $2.6 \%, P<0.001 ; 8.9 \%$ vs $2.6 \%, P<0.001)$. The length of ICU and hospital stays in the non CKD-, CKD+ and CKD- subgroups were significantly longer than in the Normal group (Table 3).

\section{Logistic regression analysis of the risk factors for postoperative AKI}

In Model 1, the multivariate logistic regression analysis showed that age, gender (male), BMI, hypertension, NYHA III-IV, CPB duration, APACHE II score in ICU admission, non CKD, CKD were independent risk factors for postoperative AKI (Table 4). In Model 2, after adjusted for all of the confounding factors in Model 1, we found that non CKD- (OR: 1.94, 95\%Cl: 1.067-3.520, $P=0.030$ ), CKD + (OR: 2.49, 95\%Cl: 1.026-6.069, $P=0.040$ ) and CKD- (OR: 8.78, 95\%Cl: $2.413-31.862, P<0.001)$ were independent risk factors for postoperative AKI, while non CKD+ (OR: 1.32, 95\% Cl: 0.901-1.927, $\mathrm{P}=0.156$ ) was not an independent risk factor (Table 4).

\section{Discussion}

In this study, we found that renal dysfunction patients both with no CKD and CKD had higher incidence of AKI than normal renal function group. However, non CKD patients with cardiac function improvement (non CKD+ group) had similar incidence of AKI with normal function group. Multivariate logistic regression revealed that non CKD+ was not a significant risk factor for postoperative AKI, and non CKD-, CKD+ and CKD- all significant increased AKI risk.

Heart and kidney disease commonly coexist in cardiac surgery patients and the definition of cardio-renal syndrome has been paid much attention since it was proposed in the Acute Dialysis Quality Initiative (ADQI) 2008 [1]. Renal dysfunction can be caused not only by chronic heart failure [2] but also by acute decompensated heart failure [3]. The Society of Thoracic Surgeons National Adult Cardiac Database reported that approximately $27 \%$ of patients undergoing isolated CABG had an eGFR $<60 \mathrm{~mL} / \mathrm{min} / 1.73$ $\mathrm{m}^{2}$ [18]. In the ADHERE study, Heywood et al. (2007) analyzed 118,465 hospitalized acute decompensated heart failure patients and found that only $9.0 \%$ had normal renal function (GFR $\geq 90$ $\mathrm{mL} / \mathrm{min} / 1.73 \mathrm{~m}^{2}$ ) and the remainder had mild to severe renal dysfunction [19]. In our study, of all the patients underwent cardiac surgery, only $8.8 \%$ with preoperative $\mathrm{SCr}>1.2 \mathrm{mg} / \mathrm{dL}$, much lower than the above studies.

Studies have shown that preoperative renal dysfunction is a major risk factor for poor prognosis $[7,8,9]$. Baseline GFR appears to be a stronger predictor of mortality even than LVEF or the New York Heart Association grade in patients with heart failure [20]. Also, in our present study, the incidence of AKI in both non CKD and CKD groups was significantly higher than normal renal function group, and both non CKD and CKD were independent risk factors for postoperative AKI. 
It is difficult to evaluate the risks and benefits of cardiac surgery for patients with renal dysfunction. On one hand, ischemia reperfusion injury, inflammation, hemolysis or oxidative stress caused by cardiopulmonary bypass all damage the kidney. However, the predominant pathophysiological mechanisms underlying acute or chronic heart failure leading to renal insufficiency are hemodynamic in nature including a reduction in cardiac output and effective circulation fluid volume, which cause low renal perfusion, renal ischemia and increase the central venous pressure; this will increase intra-abdominal pressure leading to venous congestion[21, 22]. Therefore, cardiac surgery may be still the choice for most patients as it may prevent further hypoperfusion for the kidneys.

The present study has provided important findings. According to multivariate regression analysis in Model 2, though improved cardiac function can reduce the risk of AKI for patients with non CKD and CKD, the surgery was prone to producing more disadvantages for CKD patients, possibly because of irreversible pathological changes to the kidney such as fibrosis and necrosis of the glomeruli. Thus, the AKI incidence in CKD+ group was still high as to $46.5 \%$ (Table 3 ). In addition, if cardiac function in CKD patients was not improved, not only was the incidence of AKI as high as $78.9 \%$ but also the in-hospital mortality significantly increased. For renal dysfunction patients with no CKD, the risk of AKI did not increase if cardiac function was improved, which means they may receive more benefits from surgery. In fact, it is very likely to improve the cardiac function after the surgery in a short time frame.

Our study provides new perspectives for patients with renal dysfunction about the surgical indications for cardiac surgery and the likely renal outcomes. However, the study has some limitations. First, it was a single-center retrospective study, which may has bias and needs more confirmation. Second, we are not able to follow-up the long-term outcomes of cardiac and renal functions. Furthermore, the volume-related weight gain during the surgery, and measurement of intra-abdominal pressures or other hemodynamic monitoring were not documented and considered during logistic regression this time.

\section{Conclusion}

Preoperative renal dysfunction is generally a risk factor for postoperative AKI, we hypothesize that improved cardiac function can reduce the risk; and the study demonstrated the significant differences of that between non CKD and CKD patients. For renal dysfunction patients with no CKD, the risk of postoperative AKI may not increase if the surgery was successful to improve cardiac functions, and if so, the SCr at discharge is likely to decrease compared with preoperative SCr. Whereas for CKD patients, the AKI risk would significantly increase regardless of whether the cardiac function improved or not. Thus, the surgery should not be discouraged in renal dysfunction patients without CKD if cardiac function improvement is expected. A multidisciplinary approach involving a nephrologist may help surgeons to identify high-risk patients and to consider preoperative AKI prevention measures before surgery.

\section{Abbreviations}


AKI: acute kidney injury; RRT: renal replacement therapy; SCr: serum creatinine; ICU: intensive care unit; BMI: body mass index; NYHA: New York Heart Association; LVEF: left ventricular ejection fraction; BUN: blood urea nitrogen; SCr: serum creatinine; eGFR: estimated glomerular filtration rate; CABG: coronary artery bypass grafting; OPCAB: off-pump coronary artery bypass grafting; $\mathrm{CPB}$ : cardiopulmonary bypass; CKD: chronic kidney disease; non CKD+ : non CKD \& cardiac function improved; non CKD- : non CKD \& cardiac function not improved; CKD+ : CKD \& cardiac function improved; CKD-: CKD \& cardiac function not improved

\section{Declarations}

\section{Acknowledgements}

Not applicable.

\section{Authors' contributions}

Jiarui Xu, Xiaoqiang Ding, Wenlv Lv and Jie Teng were responsible for the conception and design of the study. Jiarui Xu and Xin Chen drafted the manuscript. Jiarui Xu, Jing Lin, Yang Li, Bo shen, and Wuhua Jiang were responsible for data acquisition and analysis. Zhe Luo and Chunsheng Wang provided the patients and participated in manuscript revision. Xiaoqiang Ding, Wenlv Lv and Jie Teng read and approved the final version of the manuscript.

\section{Funding}

This study was funded by the National Natural Science Foundation of China (81901939), Shanghai Clinical Medical Center for Kidney Disease Project supported by Shanghai Municipal Health Commission (2017ZZ01015), Shanghai Public Health Improvement Action Plan (15GWZK0502); and Xiamen Science and Technology Plan in 2018 (3502Z20184009).

\section{Availability of data and materials}

Data will be made available on request.

\section{Ethics approval and consent to participate}

This study was approved by the Ethical Committee of Zhongshan Hospital affiliated to Fudan University (No. B2017-039).

\section{Consent for publication}

We received explicit consent from the patients.

\section{Competing interests}

The authors declare no conflict of interest. 


\section{References}

1. Xu JR, Zhu JM, Jiang J, et al. Risk Factors for Long-Term Mortality and Progressive Chronic Kidney Disease Associated With Acute Kidney Injury After Cardiac Surgery. Medicine (Baltimore). 2015 Nov;94(45):e2025. doi: 10.1097/MD.0000000000002025. PubMed PMID: 26559305; PubMed Central PMCID: PMCPMC4912299.

2. Jiang W, Teng J, Xu J, et al. Dynamic Predictive Scores for Cardiac Surgery-Associated Acute Kidney Injury. J Am Heart Assoc. 2016 Aug 04;5(8). doi: 10.1161/JAHA.116.003754. PubMed PMID: 27491837; PubMed Central PMCID: PMCPMC5015294.

3. Ronco C, Haapio M, House AA, et al. Cardiorenal syndrome. Journal of the American College of Cardiology. 2008 Nov 04;52(19):1527-39. doi: 10.1016/j.jacc.2008.07.051. PubMed PMID: 19007588.

4. Angelini A, Castellani C, Virzi GM, et al. The Role of Congestion in Cardiorenal Syndrome Type 2: New Pathophysiological Insights into an Experimental Model of Heart Failure. Cardiorenal medicine. 2015 Dec;6(1):61-72. doi: 10.1159/000440775. PubMed PMID: 27194997; PubMed Central PMCID: PMC4698640.

5. Vandenberghe W, Gevaert S, Kellum JA, et al. Acute Kidney Injury in Cardiorenal Syndrome Type 1 Patients: A Systematic Review and Meta-Analysis. Cardiorenal medicine. 2016 Feb;6(2):116-28. doi: 10.1159/000442300. PubMed PMID: 26989397; PubMed Central PMCID: PMC4789882.

6. Mooney JF, Chow CK, Hillis GS. Perioperative renal function and surgical outcome. Current opinion in anaesthesiology. 2014 Apr;27(2):195-200. doi: 10.1097/AC0.0000000000000054. PubMed PMID: 24509435.

7. Mehta RH, Grab JD, O'Brien SM, et al. Bedside tool for predicting the risk of postoperative dialysis in patients undergoing cardiac surgery. Circulation. 2006 Nov 21;114(21):2208-16; quiz 2208. doi: 10.1161/CIRCULATIONAHA.106.635573. PubMed PMID: 17088458.

8. Thakar CV, Arrigain S, Worley S, et al. A clinical score to predict acute renal failure after cardiac surgery. Journal of the American Society of Nephrology : JASN. 2005 Jan;16(1):162-8. doi: 10.1681/ASN.2004040331. PubMed PMID: 15563569.

9. Wijeysundera DN, Karkouti K, Dupuis JY, et al. Derivation and validation of a simplified predictive index for renal replacement therapy after cardiac surgery. Jama. 2007 Apr 25;297(16):1801-9. doi: 10.1001/jama.297.16.1801. PubMed PMID: 17456822.

10. Shavit L, Lifschitz M, Slotki I, et al. Preoperative renal dysfunction and clinical outcomes of cardiac surgery in octogenarians. Experimental gerontology. 2013 Mar;48(3):364-70. doi: 10.1016/j.exger.2013.01.012. PubMed PMID: 23388160.

11. Holzmann MJ, Sartipy U. Relation between preoperative renal dysfunction and cardiovascular events (stroke, myocardial infarction, or heart failure or death) within three months of isolated coronary artery bypass grafting. The American journal of cardiology. 2013 Nov 01;112(9):1342-6. doi: 10.1016/j.amjcard.2013.05.077. PubMed PMID: 23870631. 
12. Boerrigter G, Costello-Boerrigter LC, Abraham WT, et al. Cardiac resynchronization therapy improves renal function in human heart failure with reduced glomerular filtration rate. Journal of cardiac failure. 2008 Sep;14(7):539-46. doi: 10.1016/j.cardfail.2008.03.009. PubMed PMID: 18722318; PubMed Central PMCID: PMC2717624.

13. Sandner SE, Zimpfer D, Zrunek P, et al. Renal function and outcome after continuous flow left ventricular assist device implantation. The Annals of thoracic surgery. 2009 Apr;87(4):1072-8. doi: 10.1016/j.athoracsur.2009.01.022. PubMed PMID: 19324130.

14. Al-Sarraf N, Thalib L, Hughes A, et al. The effect of preoperative renal dysfunction with or without dialysis on early postoperative outcome following cardiac surgery. International journal of surgery. 2011;9(2):183-7. doi: 10.1016/j.jjsu.2010.11.006. PubMed PMID: 21087685.

15. National Kidney F. K/DOQI clinical practice guidelines for chronic kidney disease: evaluation, classification, and stratification. American journal of kidney diseases : the official journal of the National Kidney Foundation. 2002 Feb;39(2 Suppl 1):S1-266. PubMed PMID: 11904577.

16. Levey AS, Stevens $\mathrm{LA}$, Schmid $\mathrm{CH}$, et al. A new equation to estimate glomerular filtration rate. Ann Intern Med. 2009 May 5;150(9):604-12. PubMed PMID: 19414839; PubMed Central PMCID: PMCPMC2763564.

17. Group KDIGOKAKIW. KDIGO Clinical Practice Guiedline for Acute Kidney Injury. Kidney Int Suppl. 2012;2:1-138.

18. Cooper WA, O'Brien SM, Thourani VH, et al. Impact of renal dysfunction on outcomes of coronary artery bypass surgery: results from the Society of Thoracic Surgeons National Adult Cardiac Database. Circulation. 2006 Feb 28;113(8):1063-70. doi: 10.1161/CIRCULATIONAHA.105.580084. PubMed PMID: 16490821.

19. Heywood JT, Fonarow GC, Costanzo MR, et al. High prevalence of renal dysfunction and its impact on outcome in 118,465 patients hospitalized with acute decompensated heart failure: a report from the ADHERE database. Journal of cardiac failure. 2007 Aug;13(6):422-30. doi: 10.1016/j.cardfail.2007.03.011. PubMed PMID: 17675055.

20. Bock JS, Gottlieb SS. Cardiorenal syndrome: new perspectives. Circulation. 2010 Jun 15;121(23):2592-600. doi: 10.1161/CIRCULATIONAHA.109.886473. PubMed PMID: 20547939.

21. Cruz DN, Schmidt-Ott KM, Vescovo G, et al. Pathophysiology of cardiorenal syndrome type 2 in stable chronic heart failure: workgroup statements from the eleventh consensus conference of the Acute Dialysis Quality Initiative (ADQI). Contributions to nephrology. 2013;182:117-36. doi: 10.1159/000349968. PubMed PMID: 23689659.

22. Haase $M$, Muller $C$, Damman $K$, et al. Pathogenesis of cardiorenal syndrome type 1 in acute decompensated heart failure: workgroup statements from the eleventh consensus conference of the Acute Dialysis Quality Initiative (ADQI). Contributions to nephrology. 2013;182:99-116. doi: 10.1159/000349969. PubMed PMID: 23689658.

\section{Tables}


Table 1.

Basic characteristics of cardiac surgery patients

\begin{tabular}{|c|c|c|c|}
\hline & $\begin{array}{l}\text { RRD group } \\
(n=622)\end{array}$ & $\begin{array}{l}\text { CKD group } \\
(n=136)\end{array}$ & $\begin{array}{l}\text { Normal group } \\
(n=7,903)\end{array}$ \\
\hline \multicolumn{4}{|l|}{ Preoperative } \\
\hline Male $(n, \%)$ & $498(80.1 \%)^{a}$ & $114(83.8 \%)^{a}$ & $4,118(52.1 \%)$ \\
\hline Age (years) & $59 \pm 14^{a}$ & $63 \pm 13^{a}$ & $52 \pm 14$ \\
\hline $\mathrm{BMI}\left(\mathrm{kg} / \mathrm{m}^{2}\right)$ & $23.0 \pm 3.0$ & $24.0 \pm 3.0^{a}$ & $23.0 \pm 3.0$ \\
\hline Hypertension $(n, \%)$ & $261(42.0 \%)^{\mathrm{ab}}$ & $91(66.9 \%)^{a}$ & $2,145(27.1 \%)$ \\
\hline Diabetes mellitus $(n, \%)$ & $81(13.0 \%)$ & $23(16.9 \%)^{a}$ & $632(8.0 \%)$ \\
\hline NYHA III-IV (n, \%) & $386(62.1 \%)$ & $87(64.0 \%)$ & $4,592(58.1 \%)$ \\
\hline LVEF (\%) & $58.0 \pm 12.0^{\mathrm{a}}$ & $58.0 \pm 14.0^{a}$ & $62.0 \pm 9.0$ \\
\hline BUN (mmol/L) & $10.6 \pm 4.7^{\mathrm{a}}$ & $11.3 \pm 4.8^{a}$ & $6.3 \pm 1.9$ \\
\hline $\mathrm{SCr}(\mathrm{mg} / \mathrm{dL})$ & $1.5 \pm 0.5^{\mathrm{ab}}$ & $1.7 \pm 0.7^{\mathrm{a}}$ & $0.8 \pm 0.2$ \\
\hline eGFR $\left(\mathrm{mL} / \mathrm{min} / 1.73 \mathrm{~m}^{2}\right)$ & $62.0 \pm 22.0^{\mathrm{ab}}$ & $47.0 \pm 13.0^{a}$ & $95.0 \pm 23.0$ \\
\hline$-\geq 90 \mathrm{~mL} / \mathrm{min} / 1.73 \mathrm{~m}^{2}$ & $42(6.7 \%)$ & 0 & $4,221(53.4 \%)$ \\
\hline - $60 \sim 89 \mathrm{~mL} / \mathrm{min} / 1.73 \mathrm{~m}^{2}$ & $353(56.8 \%)$ & $11(8.1 \%)$ & $3469(43.9 \%)$ \\
\hline - $30 \sim 59 \mathrm{~mL} / \mathrm{min} / 1.73 \mathrm{~m}^{2}$ & $210(33.8 \%)$ & $95(69.8 \%)$ & $213(2.7 \%)$ \\
\hline - $15 \sim 29 \mathrm{~mL} / \mathrm{min} / 1.73 \mathrm{~m}^{2}$ & $17(2.7 \%)$ & $30(22.1 \%)$ & 0 \\
\hline Proteinuria $(n, \%)$ & $76(12.2 \%)^{a b}$ & $90(66.2 \%)^{a}$ & $417(5.3 \%)$ \\
\hline Renal ultrasound abnormal $(\mathrm{n}, \%)$ & $38(6.1 \%)^{a b}$ & $92(67.6 \%)$ & $125(1.6 \%)$ \\
\hline \multicolumn{4}{|l|}{ Intra-operative } \\
\hline \multicolumn{4}{|l|}{ Type of surgery $(n, \%)$} \\
\hline - Valve & $249(40.0 \%)$ & $52(38.2 \%)$ & $4,504(57.0 \%)$ \\
\hline - CABG/OPCAB & $156(25.1 \%)$ & $52(38.2 \%)$ & $1,463(18.5 \%)$ \\
\hline - Aorta aneurysm & $81(13.0 \%)$ & $12(8.8 \%)$ & $348(4.4 \%)$ \\
\hline - Combined & $59(9.5 \%)$ & $9(6.6 \%)$ & $197(2.5 \%)$ \\
\hline
\end{tabular}




\begin{tabular}{|llll|} 
- Others & $77(12.4 \%)$ & $11(8.1 \%)$ & $1,391(17.6 \%)$ \\
\hline CPB duration (min) & $105 \pm 44^{\mathrm{a}}$ & $94 \pm 34$ & $92 \pm 40$ \\
\hline Aortic clamping duration (min) & $59 \pm 27$ & $52 \pm 21$ & $54 \pm 26$ \\
\hline Hypotension $(n, \%)$ & $157(25.2 \%)^{\mathrm{a}}$ & $37(27.2 \%)^{\mathrm{a}}$ & $492(6.2 \%)$ \\
\hline
\end{tabular}

Note: a: compared with $C$ group, $P<0.05$; b: compared with B group, $P<0.05$

BMI: body mass index; NYHA: New York Heart Association; LVEF: left ventricular ejection fraction; BUN: blood urea nitrogen; SCr: serum creatinine; eGFR: estimated glomerular filtration rate; CABG: coronary artery bypass grafting; OPCAB: off-pump coronary artery bypass grafting; CPB: cardiopulmonary bypass;

Table 2.

AKI incidence and outcomes in different patient groups

\begin{tabular}{|llll|}
\hline & $\begin{array}{l}\text { RRD group } \\
(n=622)\end{array}$ & $\begin{array}{l}\text { CKD group } \\
(n=136)\end{array}$ & $\begin{array}{l}\text { Normal group } \\
(n=7,903)\end{array}$ \\
\hline AKI $(n, \%)$ & $246(39.5 \%)^{a b}$ & $84(61.8 \%)^{a}$ & $2371(30.0 \%)$ \\
\hline- AKI 1 & $109(17.5 \%)$ & $22(16.2 \%)$ & $1,747(22.1 \%)$ \\
\hline$-\quad$ AKI 2 & $72(11.6 \%)$ & $34(25.0 \%)$ & $371(4.7 \%)$ \\
\hline$-\quad$ AKI 3 & $65(10.5 \%)$ & $28(20.6 \%)$ & $253(3.2 \%)$ \\
\hline RRT $(n, \%)$ & $68(10.9 \%)^{a}$ & $17(12.7 \%)^{a}$ & $119(1.5 \%)$ \\
\hline Preoperative SCr $(\mathrm{mg} / \mathrm{dL})$ & $1.7 \pm 0.8$ & $1.6 \pm 0.6$ & $0.8 \pm 0.2$ \\
\hline SCr at discharge $(\mathrm{mg} / \mathrm{dL})$ & $1.6 \pm 1.1$ & $2.3 \pm 1.4^{\star}$ & $0.9 \pm 0.5$ \\
\hline Length of ICU stay $(\mathrm{h})$ & $46[23,96]^{\mathrm{a}}$ & $70[43,132]^{\mathrm{a}}$ & $26[21,65]$ \\
\hline Length of hospital stay $(\mathrm{d})$ & $18 \pm 13^{\mathrm{a}}$ & $20 \pm 9^{\mathrm{a}}$ & $14 \pm 10$ \\
\hline Mechanical ventilation days & $1[1,2]$ & $1[1,2]$ & $1[1,2]$ \\
\hline Hospital mortality $(n, \%)$ & $38(6.1 \%)^{\mathrm{a}}$ & $14(10.3 \%)^{\mathrm{a}}$ & $205(2.6 \%)$ \\
\hline
\end{tabular}

Note: a: compared with $\mathrm{C}$ group, $P<0.05$; b: compared with $\mathrm{B}$ group, $P<0.05$; * comparing $\mathrm{SCr}$ at discharge with preoperative $\mathrm{SCr}$ in the same group, $P<0.05$.

AKI: acute kidney injury; RRT: renal replacement therapy; SCr: serum creatinine; ICU: intensive care unit. 
Table 3.

AKI incidence and outcomes in different patient sub-groups

\begin{tabular}{|c|c|c|c|c|c|}
\hline & $\begin{array}{l}\text { RRD+ } \\
\text { group } \\
(n=363)\end{array}$ & $\begin{array}{l}\text { RRD- group } \\
(n=259)\end{array}$ & $\begin{array}{l}\text { CKD+ } \\
\text { group } \\
(n=71)\end{array}$ & $\begin{array}{l}\text { CKD- group } \\
(n=65)\end{array}$ & $\begin{array}{l}\text { Normal } \\
\text { group } \\
(n=7,903)\end{array}$ \\
\hline $\operatorname{AKI}(n, \%)$ & $\begin{array}{l}112 \\
(30.9 \%)\end{array}$ & $\begin{array}{l}134 \\
(51.7 \%)^{a}\end{array}$ & $\begin{array}{l}33 \\
(46.5 \%)^{a}\end{array}$ & $51(78.9 \%)^{a}$ & $\begin{array}{l}2,371 \\
(30.0 \%)\end{array}$ \\
\hline - $\quad$ AKI 1 & $57(15.7 \%)$ & $52(20.1 \%)$ & $10(14.1 \%)$ & $12(18.5 \%)$ & $\begin{array}{l}1,747 \\
(22.1 \%)\end{array}$ \\
\hline - $\quad A K I 2$ & $32(8.8 \%)$ & $40(15.4 \%)$ & $12(16.9 \%)$ & $22(33.8 \%)$ & $371(4.7 \%)$ \\
\hline - $\quad A K I 3$ & $23(6.3 \%)$ & $42(16.2 \%)$ & $11(15.5 \%)$ & $17(26.2 \%)$ & $253(3.2 \%)$ \\
\hline $\operatorname{RRT}(n, \%)$ & $32(8.8 \%)^{\mathrm{a}}$ & $33(12.7 \%)^{a}$ & $\begin{array}{l}12 \\
(16.9 \%)^{a}\end{array}$ & $8(12.3 \%)^{a}$ & $119(1.5 \%)$ \\
\hline $\begin{array}{l}\text { Preoperative SCr } \\
(\mathrm{mg} / \mathrm{dL})\end{array}$ & $1.7 \pm 0.9$ & $1.7 \pm 0.7$ & $1.6 \pm 0.7$ & $1.5 \pm 0.4$ & $0.8 \pm 0.2$ \\
\hline $\begin{array}{l}\text { SCr at discharge } \\
(\mathrm{mg} / \mathrm{dL})\end{array}$ & $1.4 \pm 0.8^{*}$ & $1.9 \pm 1.6$ & $2.0 \pm 1.1$ & $2.5 \pm 1.7 *$ & $0.9 \pm 0.5$ \\
\hline Length of ICU stay (h) & $44[22,91]$ & $\begin{array}{l}75[24,139] \\
\text { a }\end{array}$ & $\begin{array}{l}66[24 \\
113]^{a}\end{array}$ & $\begin{array}{l}103[47, \\
235]^{\mathrm{a}}\end{array}$ & $26[21,65]$ \\
\hline $\begin{array}{l}\text { Length of hospital stay } \\
\text { (d) }\end{array}$ & $18 \pm 7$ & $19 \pm 11^{a}$ & $18 \pm 13^{a}$ & $24 \pm 15^{a}$ & $14 \pm 10$ \\
\hline Hospital mortality $(n, \%)$ & $15(4.1 \%)$ & $23(8.9 \%)^{a}$ & $4(5.6 \%)$ & $10(15.4 \%)^{\mathrm{a}}$ & $205(2.6 \%)^{\mathrm{C}}$ \\
\hline
\end{tabular}

Note: a: compared with $\mathrm{C}$ group, $P<0.05$; ${ }^{*}$ comparing $\mathrm{SCr}$ at discharge with preoperative $\mathrm{SCr}$ in the same group, $P<0.05$.

AKI: acute kidney injury; RRT: renal replacement therapy; SCr: serum creatinine; ICU: intensive care unit 
Table 4.

Multivariate logistic regression analysis of risk factors for postoperative AKI in patients underwent cardiac surgery

\begin{tabular}{|c|c|c|c|}
\hline & OR & $95 \% \mathrm{Cl}$ & $P$-value \\
\hline \multicolumn{4}{|l|}{ Model 1} \\
\hline Age (every year added) & 1.03 & $1.027-1.040$ & $<0.001$ \\
\hline Gender (male) & 1.95 & $1.672-2.271$ & $<0.001$ \\
\hline BMI & 1.04 & $1.018-1.079$ & 0.027 \\
\hline Hypertension & 1.29 & $1.080-1.533$ & 0.005 \\
\hline NYHA III-IV & 1.27 & $1.083-1.490$ & 0.003 \\
\hline Aorta surgery & 2.12 & $1.453-7.816$ & $<0.001$ \\
\hline CPB time (every minute added) & 1.01 & $1.009-1.013$ & $<0.001$ \\
\hline Intraoperative hypotension & 3.98 & $2.187-8.238$ & $<0.001$ \\
\hline \multicolumn{4}{|l|}{ Preoperative renal function: } \\
\hline - Normal & reference & - & - \\
\hline - RRD & 1.89 & $1.363-3.670$ & $<0.001$ \\
\hline - CKD & 3.45 & $1.562-7.646$ & 0.002 \\
\hline \multicolumn{4}{|c|}{ Model 2 (adjusted by above factors) } \\
\hline \multicolumn{4}{|l|}{ Preoperative renal function: } \\
\hline - Normal & reference & - & - \\
\hline$-\mathrm{RRD}+$ & 1.32 & $0.901-1.927$ & 0.156 \\
\hline - RRD - & 1.94 & $1.067-3.520$ & 0.030 \\
\hline$-\quad C K D+$ & 2.49 & $1.026-6.069$ & 0.040 \\
\hline - CKD - & 8.78 & $2.413-31.862$ & $<0.001$ \\
\hline
\end{tabular}

Note: BMI: body mass index; NYHA: New York Heart Association; CPB: cardiopulmonary bypass

Figures 


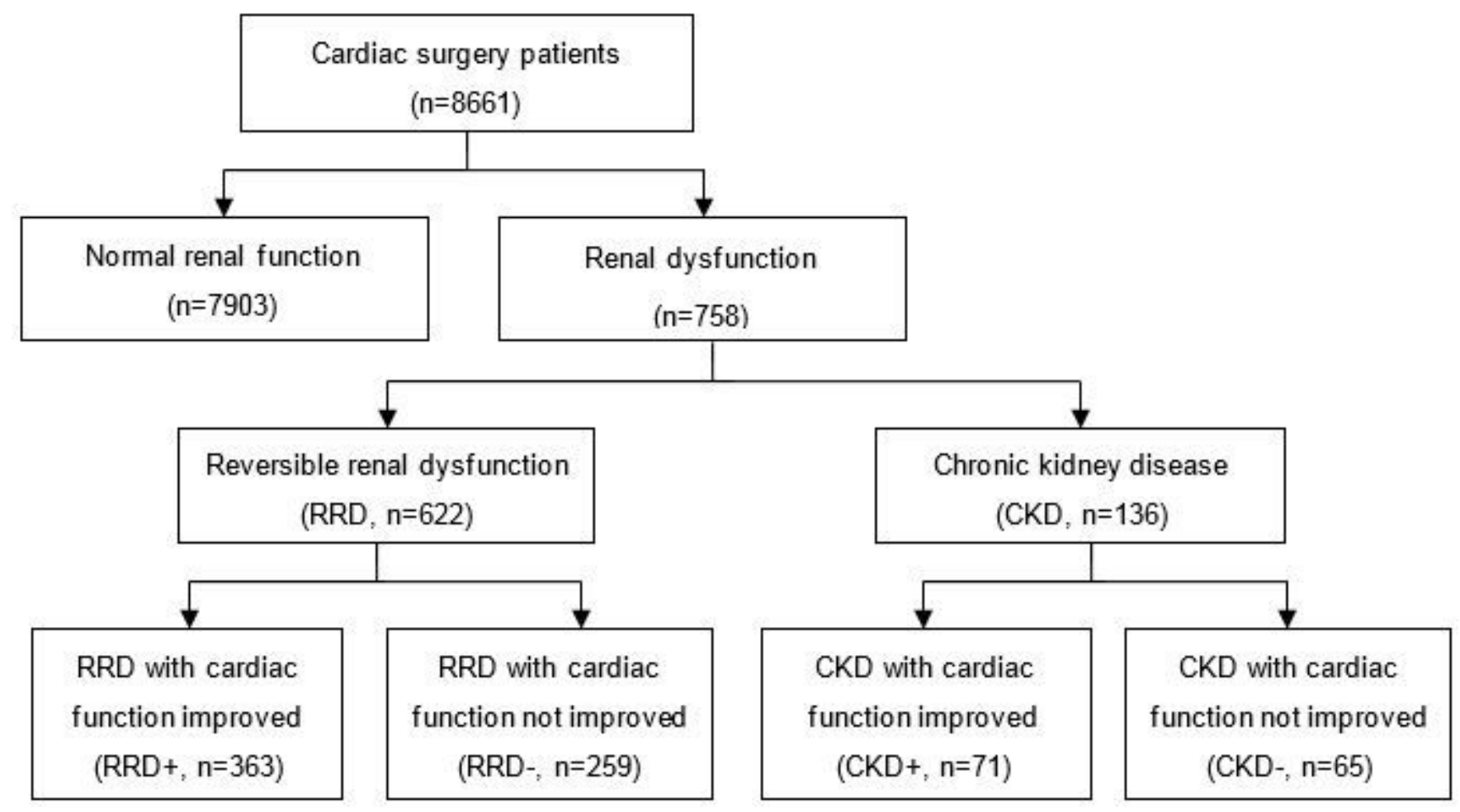

Figure 1

Flow chart of the study 